\title{
Problems of the dynamic test method for individual protection equipment (shock absorbers)
}

\author{
Dmitry Korolchenko ${ }^{1, *}$, Vasily Vasilenko ${ }^{1}$, and Georgy Lelikov ${ }^{1}$ \\ ${ }^{1}$ Moscow State University of Civil Engineering, Yaroslavskoe shosse, 26, 129337, Moscow, Russia
}

\begin{abstract}
This paper examines issues of safety of high-altitude works, using individual protection equipment to prevent falling from a height. In particular, the paper reviews personal protective equipment - shock absorber, its dynamic characteristics and related test methods to meet the requirements of Technical Regulations 019/2011 "Safety of Individual Protection Equipment". The paper discusses the differences between the Russian and European standards for dynamic characteristic testing of shock absorbers, even as the former are harmonized texts of the latter, and the effect of such differences on protective performance of shock absorbers and ultimately on safety of works on heights. It have been shown that tests, conducted in accordance with the Russian regulative documents for dynamic performance of the shock absorbers, entail decreasing in safety usage of such type of IPE and increasing in injuries during falls from a height. It has been defined necessity to actualize the range of the testing system of shock absorbers, and to admit its larger value that will cause increase in protective properties of shock absorbers.
\end{abstract}

\section{Introduction}

Falling from heights certainly stands apart as a cause of accidents in the construction sector. This cause of injuries accounts for $30 \%$ of all grave and lethal statistics, and the ratio will top $35 \%$ if we examine fatalities [1-8]. To ensure safe operation on heights, use of individual protection equipment (IPE) to prevent falling from heights is an option. After the Customs Union Technical Regulations No TP TC 019/2011 "Safety of Individual Protection Equipment" was enacted, all IPE is to pass the mandatory certification procedure to meet the provisions of the said Technical Regulations [9-11]. The certification sequence includes an item that calls for certification testing of IPE using the methodology described in the enclosure to TP TC 019/2011.

One of the major components of any IPE is a shock absorber designed to absorb the kinetic energy generated when a person falls from height and to make the stop after falling softer [12-14]. Methodologies that regulate tests of such IPE are set forth in GOST R EH 355. "Individual protection equipment to prevent falling from heights. Shock absorbers". General Technical Requirements. Testing Methods» [15], and GOST R 12.4.206 - 99.

\footnotetext{
*Corresponding author: ikbs@mgsu.ru
} 
"Individual protection equipment to prevent falling from heights. Testing Methods" [16]. Said standards are authentic versions of regional standards EN 355 "Occupational Safety Standards System. Personal Protective Equipment against Falls from a Height. Energy Absorbers. General Technical Requirements. Test Methods" [17], and EN 364 "Personal Protective Equipment against Falls from a Height - Test Methods" [18], respectively. One of the key testing methods described in the methodology [15-18] is that for dynamic characteristics [19-20]. Tests revealed that the Russian standards failed to comply with their European counterparts of which they are expected to be authentic version texts. Among other things, the "area of discord" is the length of the overall system to be subject to dynamic testing, and consequently that of the emerging dynamic loads. The GOST Federal Standard [15] names $2 \pm 0.25 \mathrm{~m}$ as the permissible length of the entire dynamic test system, whereas EN [17] requires such length to be $2+0.25 \mathrm{~m}$. Obviously, the Russian standard allows a wider range, while tests can address a shorter leg of the testing system, and this in turn results in lower dynamic loads during the test, with lower requirements presented to the protective properties of shock absorbers [10]. The purpose of this research is updating the Federal Standard [14], particularly par. 5, 4, and analysis of the use of an extended range for the testing system during dynamic characteristic tests of shock absorbers. To achieve the target, we conducted the dynamic characteristics of shock absorbers to register their key figures: greatest braking force and safety line length.

\section{Materials and methods}

The tests were conducted to meet the GOST methodology $[15,16]$. A shock absorber control sample consists of a set of textile belts sewn together and laid inside a plastic housing. To generate dependency curves representing dynamic characteristics dependency on the testing system length (L), we conducted dynamic tests and registered readings of dynamic characteristics taken at five points over the range of $\mathrm{L}=2 \pm 0.25 \mathrm{~m}$.

The entire testing cycle occurred on the test bench for individual protection equipment used to prevent human falling from height [20]. The test bench consists of two sections:

- static, which activated samples with prior static load of $2 \mathrm{kN}$ for $3 \mathrm{~min}$. (Fig. 1);

- dynamic, in the working space of which we reset the testing system after the shock absorbers were activated (Fig. 1).

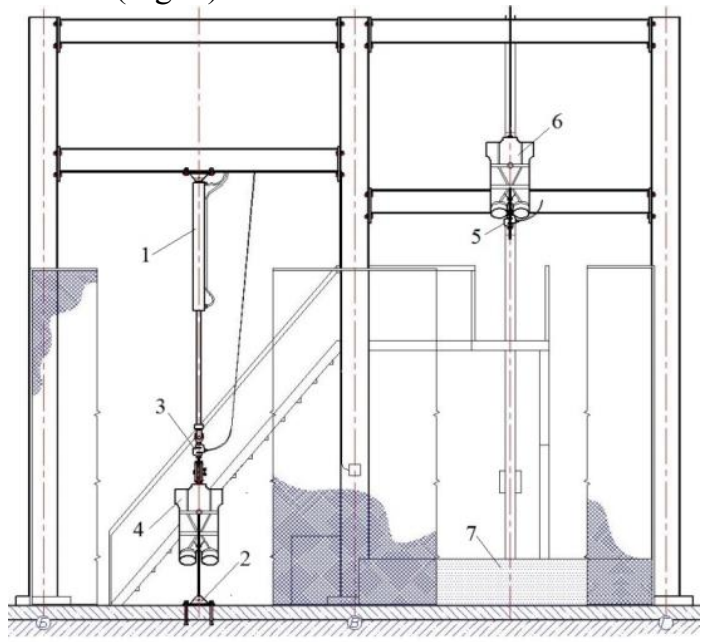

Fig. 1. Diagram of test bench for individual protection equipment for falling from height, $1-$ hydraulic cylinder, 2 - anchoring power point, 3 - static testing dynamometer; 4,6 - test dummy; 5 testing dynamometer; 7 - absorbing cushion. 
Before the prior static load test, we measure the length of the shock absorber $\left(1_{1}\right)$; then the shock absorber is fixed in the static section of the test bench. After the control sample is set, it is put under static load of $2 \mathrm{kN}$ for $3 \mathrm{~min}$. Then we measure the length of the shock absorber $\left(1_{2}\right)$, and observe the sample's activation $\Delta \mathrm{l}=\mathrm{l}_{2}-\mathrm{l}_{1}$. Activation of the shock absorber may not exceed $50 \mathrm{~mm}$ under the GOST [15]. It the condition is true, we can proceed with the dynamic test.

Dynamic characteristics are tested with a weight of $100 \mathrm{~kg}$. First, we assemble the testing system. To do so, we connect a load of $100 \mathrm{~kg}$ to one end of the shock absorber (testing sample); to the other end we connect a chain that meets the GOST [16]. Total length of the system assembled must be $\mathrm{L}=2 \pm 0.25 \mathrm{~m}$. In our case, we are varying the system length from the greatest to the least value. As our next step following assembly of the testing system, we connect the free end of the chain with the joining element that has the meter fixed in the anchor point; then we raise the load to the initial position so it can be dropped down (Fig. 2).

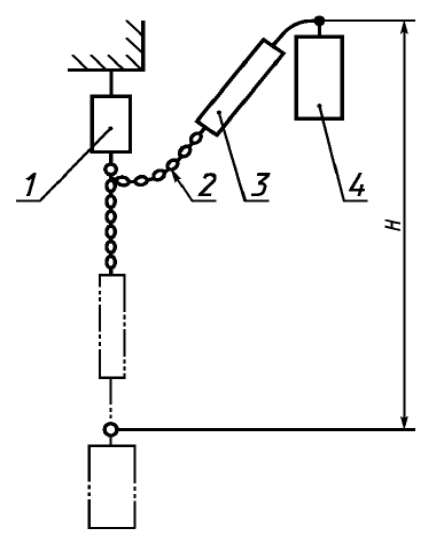

Fig. 2. Dynamic load testing diagram. Where: 1- strength meter sensor, 2 - chain to adjust the testing system length, 3- shock absorber, 4 - $100 \mathrm{~kg}$ weight, $\mathrm{H}$ - secured area, $\mathrm{m}$.

Vertical distance measured between the points of application of the force in the connecting subsystem, from the initial position (beginning of free fall) to the final position (state of equilibrium after the fall stops).

Having raised the control weight to the full length of the testing system, we drop it, at initial zero speed by activating the tripping device. As it performs its function, the shock absorber reduces the kinetic energy and gets somewhat longer. The test should find: $F_{\max }-$ maximum braking force, safety area $\mathrm{H}$, based on behavior of the control sample. To simplify perception of the results, we substitute $\mathrm{H}$ (safety section) with the notion of shock absorber extension. Formula $\mathrm{H}<2 \mathrm{~L}+1.75$ demonstrates that figure $1.75 \mathrm{~m}$ is the greatest permissible extension of the shock absorber. Let us write the control sample extension as B (m). The condition of compliance under par. 4of the methodology [15] and par. 4, item 21 of the Technical Regulation [9] is: braking force $\mathrm{F}_{\max }$ not above $6 \mathrm{kN}$, and the safety area $\mathrm{H}<$ $2 \mathrm{~L}+1.75 \mathrm{~m}$; where $\mathrm{L}$ is full length of the shock absorber upon activation, including the length of the chain sling, plus connection elements. We now substitute the value $\mathrm{B}$ with $\mathrm{H}$, to find the permissible extensions of the shock absorber as $\mathrm{B}<1.75 \mathrm{~m}$.

\section{Results and discussion}

Table 1 presents the results of key dynamic constructions read from five different versions of the testing system; and the value of prior activation of the samples. 
Table 1. Consolidated table of dynamic characteristics.

\begin{tabular}{|l|l|l|l|l|}
\hline S/no & $\mathrm{L}(\mathrm{m})$ & $\mathrm{F}_{\max }(\mathrm{kN})$ & $\mathrm{B}(\mathrm{m})$ & $\Delta \mathrm{l}(\mathrm{mm})$ \\
\hline 1 & 1.75 & 5.3 & 0.96 & 14 \\
\hline 2 & 1.875 & 5.8 & 1.12 & 10 \\
\hline 3 & 2 & 6.2 & 1.2 & 12 \\
\hline 4 & 1.875 & 6.7 & 1.2 & 31 \\
\hline 5 & 2.25 & 7.9 & 1.43 & 22 \\
\hline
\end{tabular}

Fig. 3 gives a diagram of kinetic energy absorption; axis $\mathrm{X}$ plots the values of the load as $\mathrm{kN}$; axis Y represents time (sec). Fig. 3 has a diagram of kinetic energy absorption by the shock absorber within the range in question, specifically $\mathrm{L}=2.25 \mathrm{~m}$.

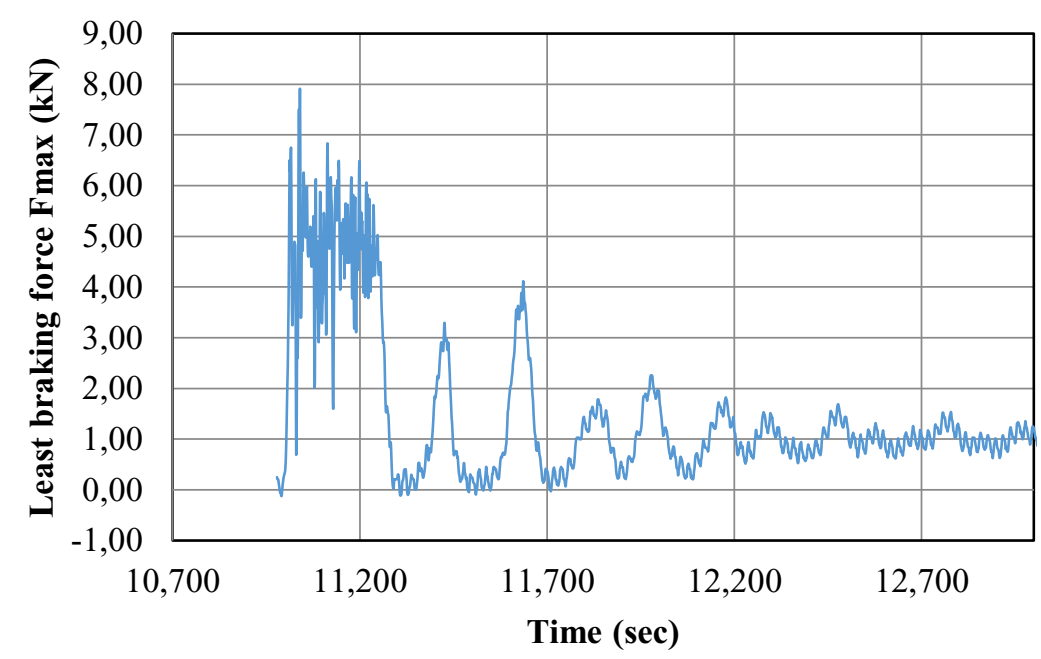

Fig. 3. Diagram showing absorption of kinetic energy under $\mathrm{L}=2.25 \mathrm{~m}$.

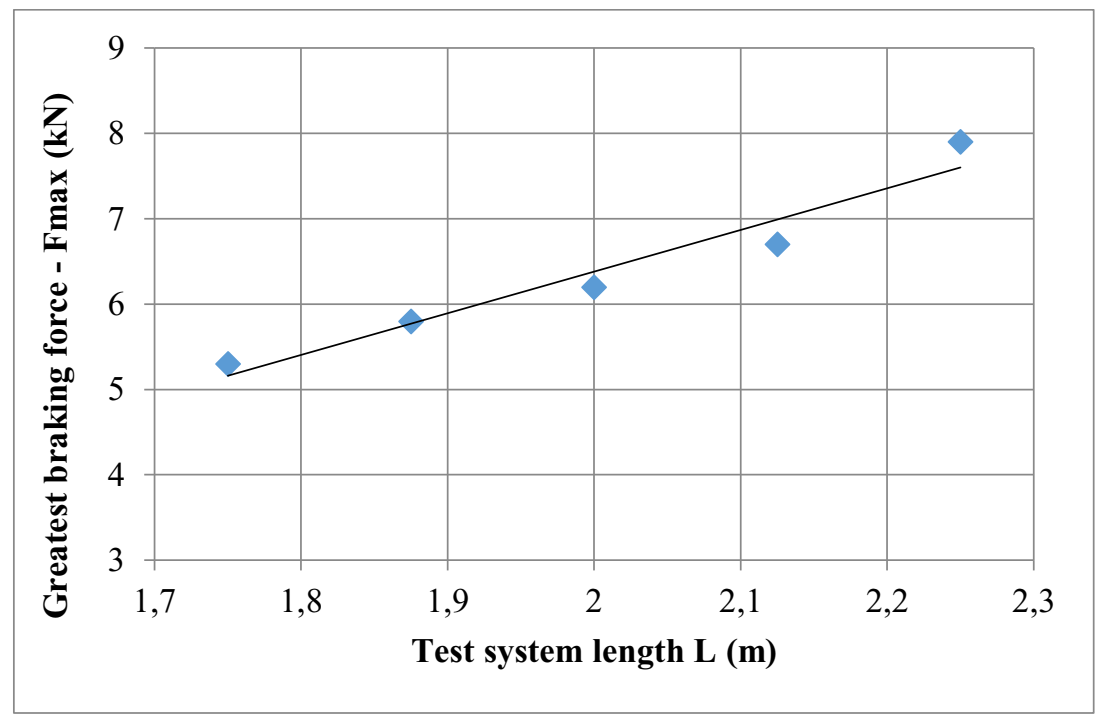

Fig. 4. Dependency of greatest braking force $F_{\max }$ on test system length $\mathrm{L}$. 
We use the dynamic characteristic figures from Table 1 to represent their dependencies. While we process the $\mathrm{F}_{\max }$ to $\mathrm{L}$ ratio, we approximate it to the linear function. The resulting value of $\mathrm{f}(\mathrm{x})=4.88 \mathrm{x}-3.38$ has the consistency of approximation at $\mathrm{R}^{2}=0.942$, and this means that the function reliably represents the resulting distribution of points. To build the function, we used the least squares method [21-23], while the optimality criterion was the least total of the squares of differences between calculated values of $f\left(x_{i}\right)$ and $y_{i}$ values used as basis to build the original diagram. Now in Fig. 5 we show the ratio of shock absorber extension to the greatest braking force. The diagrams of kinetic energy absorption show greatest braking force $F_{\max }$, the number and values of dynamic burst peaks, and such critical indicator as acceleration time $(\mathrm{T})$ the person has to experience during a fall. Because the value of (T) is still unregulated by any authority as regards IPE test requirements, we are not going to scrutinize it here, but it is of great interest and critical for safety and injury probability for a person falling from height.

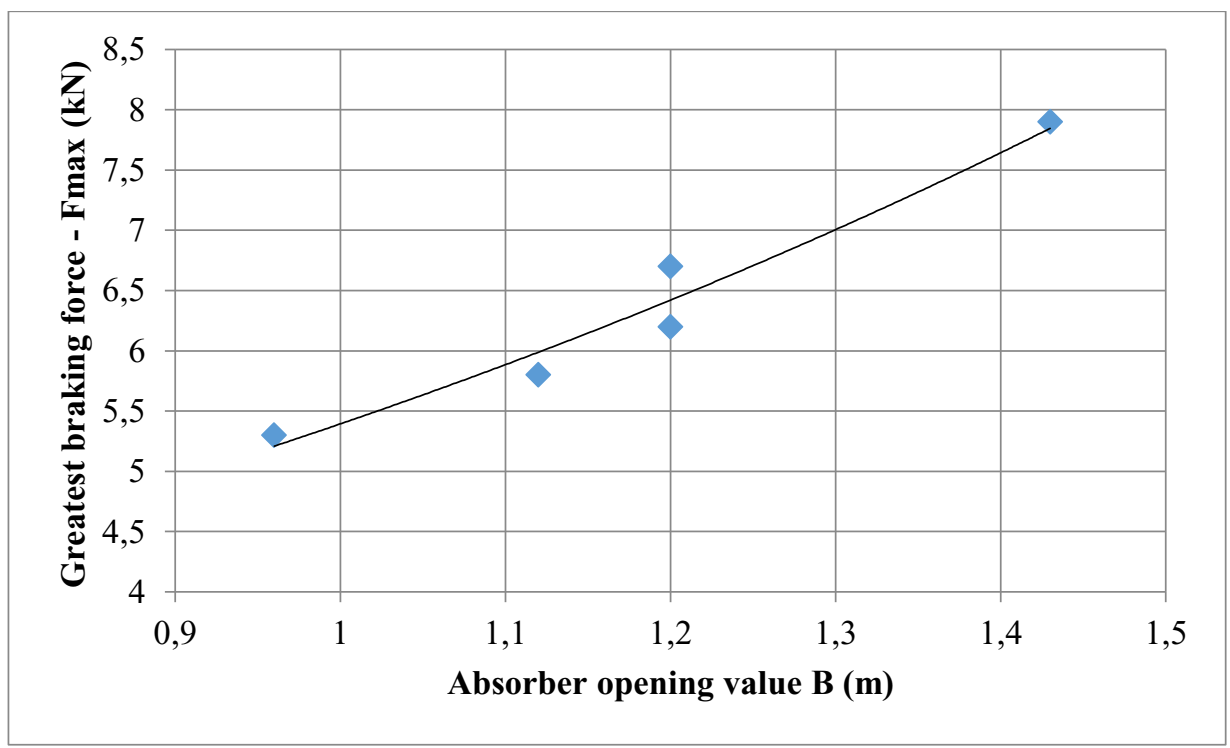

Fig. 5. Dependency of shock absorber opening $B$ on greatest braking force $F_{\text {max }}$.

The diagram in Fig. 4 is mostly of interest as it is relevant for this paper's objective. The diagram shows that the $F_{\max }$ value range recorded during the tests under the GOST standard methodology [15] is $2.6 \mathrm{kN}$. The nature of $\mathrm{F}_{\max }$ to $\mathrm{L}$ ratio (Fig. 4) can be described with linear dependency function $\mathrm{f}\left(\mathrm{F}_{\max }\right)=\mathrm{k} \times \mathrm{L}+\mathrm{b}$. Another important parameter regulated by the methodology [15] is the opening of the shock absorber. Fig. 5 represents the dependency of $\mathrm{B}$ on $\mathrm{F}_{\max }$ values; as we can service, an increase of the greatest braking force causes an increase of the shock absorber opening.

\section{Conclusions}

At this time, the regulations $[9,15,24,25]$ define the requirement to the greatest braking force for a person falling from heights, as follows: in safety systems designed to stop falling, the force acting for a person falling from a height may not exceed $6 \mathrm{kN}$ with a safety halyard used.

Our research established that to meet the standard GOST requirements [16], spread of the greatest braking force was $2.6 \mathrm{kN}$, which was $43 \%$ of the required level. This results in a situation where the shock absorber tested at the lowest value of $\mathrm{L}$ shows Fmax $=5.3 \mathrm{kN}$. If 
the test range were compliant under the EN [17], then even with the minimum L requirement, the force was $6.2 \mathrm{kN}$, and the sample failed the requirements of the Technical Regulation [9] and the GOST [15]. The same situation exists with the other parameter (B), which grows along with the falling height. Under our research, the value of B should not go beyond the regulated range [15] in the test range of the GOST [16], as stated in par. 5.3.4.1.1. However, with the lowest $\mathrm{L}$, the value of $\mathrm{B}$ will be close to the regulated $1.75 \mathrm{~m}$, and within the EN range [17] it gets beyond the permissible limits.

The above demonstrates that if tests are held under the GOST [16] par. 5.3.4.1.1, requirements presented to dynamic characteristics of the shock absorber are lowered. Such situation compromises safety of this type of IPE and raises the injury rate in case of a person falling from a height. Therefore, we believe that the range of the shock absorber testing system should be reviewed and readjusted upwards to the value of $L=2+0.25$. This will cause an improvement in the protective properties of shock absorbers.

\section{References}

1. G.S. Rashitov, G.M. Abdiukova, Collection of Science Reports by Participants of Russian National Practical Science Conference, with international contributors 2, 286 (2015)

2. E.A. Savelyeva, Science and Technology Journal Ugol 11, 45-46 (2016)

3. V.A. Senchenko, T.T. Kaverzneva, Industrial and Occupational safety 3(64), 71-76 (2015)

4. V.A. Senchenko, Industrial and Occupational safety 3(68), 67-69 (2016)

5. S.L. Pushenko, E.V. Staseva, Bulletin of Volgograd State Architecture and Civil Construction University. Series: Architecture and Civil Construction 44(63), 157-165 (2016)

6. M.S. Ovcharenko, Collection of Science Research Publications from the Fourth International Youth Science Conference, 4 volumes: "Future Generation: Young Scientists View 3, 259-262 (2015)

7. E.A. Nadhim, C. Hon, B. Xia, I. Stewart, D. Fang, Int. J. Environ. Res. Public Health 13, 638 (2016)

8. B. Hoła, Journal of Civil Engineering and Management 16(4), 577-585 (2010)

9. Customs Union Technical Regulation, TRTS 019/2011 "Safety of Individual Protection Equipment"

10. V.E. Rodin, A.A. Perevezencev, Industrial and Occupational Safety 2, 59-63 (2013)

11. A.Ya. Korolchenko, E.A. Petrova, Zhurnal Rossijskogo Khimicheskogo Obshchestva Im. D.I. Mendeleeva 47(4), 49-55 (2003)

12. An. Mottaeva, V. Lukinov, As. Mottaeva, Economy and entrepreneurship 8 (49), 34-37 (2014)

13. R. Irles, J.C. Pomares, E.G. Segovia, M.B. Ferrer, E.A. Carrion, Conference Paper Structures Under Shock and Impact XIII 405-416 (2014)

14. Yu.N. Shebeko, A.Ya. Korolchenko, E.D. Zamishevski, A.V. Trunev, V.Yu. Navzenya, A.A. Zaitzev, Combustion and Flame 117(1-2), 438-440 (1999) DOI: 10.1016/S00102180(98)00107-2

15. Russian Standard GOST R EN $355-2008$

16. Russian Standard GOST R 12.4.206-99 
17. European Norms EN 355:2002

18. European Norms EN 364:1992

19. Y.M. Goh, E.D. Peter, Safety Science 48, 747-754 (2010)

20. A.A. Stupakov, P.D. Kapirin, G.D. Lelikov, P.A. Semionov, V.V. Vasilenko, MGSU Bulletin 8, 130-139 (2015)

21. Yu.V. Linnik, Least Squares Method and Foundations of Observation Processing Theory (GIFML, Moscow, 1958)

22. D. Korolchenko, A. Tusnin, S. Trushin, A. Korolchenko, International Journal of Applied Engineering Research 10(21), 42541-42548 (2015)

23. V.A. Markeev, S.S. Voevoda, D.A. Korolchenko, Neftyanoe khozyaystvo - Oil Industry 9, 83-85 (2006)

24. D. Korolchenko, V. Kholshchevnikov, MATEC Web of Conferences 106, 01038 (2017) DOI: $10.1051 /$ matecconf $/ 201710601038$

25. Safety Rules for Works on Heights, RF Labor and Social Security Ministry Order No. 155n dated 28.03.2014 "Enacting the Safety Rules for Works on Heights", Registration No. 33990 